\title{
Soy protein isolate/bioactive glass composite membranes: Processing and properties
}

Tansaz, S ; Schulte, M ; Kneser, U ; Mohn, D ; Stark, W ; Roether, J A ; Cicha, I ; Boccaccini, A R

\begin{abstract}
Composite biomaterials based on proteins and inorganic fillers are highly attractive for wound dressing applications due to their highly absorbent properties towards blood and exudate provided by the inorganic fillers. Moreover, such composites offer a desirable environment for cells due to the combination of organic and inorganic characteristics. This study highlights the fabrication of soy protein isolate/nanoscale bioactive glass composite films by solvent casting method as a matrix for wound-dressing applications. The effect of the addition of bioactive glass nano particles on blood clotting was assessed. Cytotoxicity and in vitro cytocompatibility of the films were also tested. The results showed that the composite films could meet the essential requirements for an appropriate wound dressing with additional favorable properties such as hemostatic capability and mechanical properties as well as significant cell cytocompatibility.
\end{abstract}

DOI: https://doi.org/10.1016/j.eurpolymj.2018.07.003

Posted at the Zurich Open Repository and Archive, University of Zurich

ZORA URL: https://doi.org/10.5167/uzh-167394

Journal Article

Accepted Version

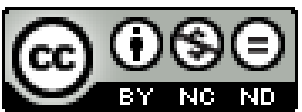

The following work is licensed under a Creative Commons: Attribution-NonCommercial-NoDerivatives 4.0 International (CC BY-NC-ND 4.0) License.

Originally published at:

Tansaz, S; Schulte, M; Kneser, U; Mohn, D; Stark, W; Roether, J A; Cicha, I; Boccaccini, A R (2018). Soy protein isolate/bioactive glass composite membranes: Processing and properties. European Polymer Journal, 106:232-241.

DOI: https://doi.org/10.1016/j.eurpolymj.2018.07.003 


\title{
Soy protein isolate/bioactive glass composite membranes: processing and properties
}

S. Tansaz * a , M. Schulte ${ }^{b}$, U. Kneser ${ }^{b}$, D. Mohn ${ }^{\text {c, d, W. Stark }}{ }^{\text {c }}$, J. A. Roether ${ }^{\text {e }}$, I. Cicha ${ }^{f}$, A. R. Boccaccini. * a

${ }^{a}$ Institute of Biomaterials, University of Erlangen-Nuremberg, Cauerstr.6, 91058 Erlangen, Germany

b Department of Hand, Plastic and Reconstructive Surgery-Burn Center, BG Trauma Center Ludwigshafen/Rhine, Hand and Plastic Surgery, University Heidelberg, Ludwig-Guttmann-Str. 13, Ludwigshafen, Germany

${ }^{\mathrm{c}}$ Department of Chemistry and Applied Biosciences, Institute for Chemical and Bioengineering, ETH Zurich, Switzerland

${ }^{\mathrm{d}}$ Clinic of Preventive Dentistry, Periodontology and Cariology, University of Zurich, Centre of Dental Medicine, Plattenstr. 11, CH-8032 Zurich, Switzerland

e Institute for Polymer Materials, Department of Materials Science and Engineering, University of Erlangen-Nuremberg, Erlangen, Germany

f Section of Experimental Oncology and Nanomedicine, ENT-Department, University Hospital Erlangen, Germany

* Corresponding authors. Email addresses: aldo.boccaccini@ww.uni-erlangen.de samira.tansaz@fau.de

\begin{abstract}
Composite biomaterials based on proteins and inorganic fillers are highly attractive for wound dressing applications due to their highly absorbent properties towards blood and exudate provided by the inorganic fillers. Moreover, such composites offer a desirable environment for cells due to the combination of organic and inorganic characteristics. This study highlights the fabrication of soy protein isolate/nanoscale bioactive glass composite films by solvent casting method as a matrix for wound-dressing applications. The effect of the addition of bioactive glass nano particles on blood clotting was assessed. Cytotoxicity and in vitro cytocompatibility of the films were also tested. The results showed that the composite films could meet the essential requirements for an appropriate wound dressing with additional favorable properties such as hemostatic capability and mechanical properties as well as significant cell cytocompatibility.
\end{abstract}




\section{Keywords}

Soy protein isolate; bioactive glass; cytocompatibility; clotting assay; wound dressing

\section{Introduction}

Naturally derived materials like proteins are widely investigated in biomedical applications. In this regard, soy protein is considered to exhibit beneficial properties over other proteins such as high storage capability, being of non-animal origin and inexpensive [1]. Many reports have been published about biomedical applications of pure soy protein or blending with other polymers or macromolecules [2-9]. For instance, it was found that soy protein granules could be used as inexpensive bone fillers due to their mechanical stability, anti-inflammatory capability and ability to induce osteoblast differentiation by the action of intrinsic isoflavones in vitro $[4,5]$ and in vivo [6]. Other studies have shown that soy protein films were nontoxic and promoted cell proliferation [7] while soy membranes with controlled antibacterial release could be an option for wound dressing applications [8]. Moreover, soy protein/alginate hydrogel films were shown to support the attachment, spreading, and proliferation of mouse fibroblast cells for soft tissue engineering applications [9].

Bioactive glasses (BGs) such as other inorganic materials are attractive materials for hard tissue engineering, like in bone and dental regeneration. Recently, BGs have started to be considered for soft tissue regeneration and wound healing applications [10]. For instance, Ostomel et al. [11] used silicate glasses as hemostasis inducing materials for blood clot formation, highlighting that bioactive glasses can release $\mathrm{Ca}^{+2}$ ions to support the coagulation cascade [11]. In another study [12], 1\% silver doped mesoporous bioactive glass showed no toxicity against fibroblasts in addition to inducing an antibacterial effect. Bioactive glass containing biopolymers are therefore an alternative option for treating burn wounds [12]. Moreover, bioactive glasses exhibit angiogenic capacity due to the effect of ionic dissolution products [13] release and can therefore be used as wound healing materials. However, due to the brittleness and sharp morphology of bioactive glass particles, which can create inflammatory response or cell damage, BG particles are usually combined with biopolymers forming composite materials for wound healing applications [14]. BG particles alone do not have appropriate mechanical stability for wound treatment and due to their sharp morphology they can induce inflammatory reactions [14]. Therefore, the development of new organicinorganic composite biomaterials which have proper mechanical properties and degradability while maintaining other bioactive attributes of inorganic components is inevitable for soft 
tissue engineering and wound healing applications. In this context, the combination of BGs and biodegradable polymers to attain flexible composites for soft tissue engineering and wound healing is gaining increasing interest [14-17]. For example, Moura et al. [17] fabricated composite electrospun fibrous membranes containing polycaprolactone incorporating silver-cobalt doped bioactive glass nanoparticles for wound healing applications. Ma et al. [18] fabricated composite BG-gelatin/chitosan nanofibrous membranes by electrospinning to develop biomaterials for repairing chronic and non-healing wounds. Zeng et al. [19] illustrated that composite BG-alginate/agarose hydrogels promoted cell migration and angiogenesis both in vitro and in vivo by providing a suitable moist environment and releasing bioactive ions for chronic wound healing.

The main goal of this investigation was the fabrication of soy protein isolate membranes with and without addition of bioactive glass nanoparticles intended for applications as wound dressing materials exploiting the complementary properties of both biomaterials. In this study the complete characterization of the membranes is presented, such as mechanical properties, clotting capability, degradation behavior and in vitro cytocompatibility.

\section{Materials and methods}

\subsection{Materials}

Two different kinds of soy protein isolate (SPI) containing minimum $90 \mathrm{wt}$ \% protein were acquired from NowSports (England) and MP Biomedicals (USA). Some of the characterization experiments were done only on films produced by soy protein isolate from NowSports. This is a human dietary product containing also some minerals and additives, such as iron and sugar, therefore, the SPI from MP Biomedicals was chosen for further investigations. Glycerol was purchased from VWR International (Belgium). Three different kinds of nanosized bioactive glass (nBG) particles were considered (mean particle size 20-80 $\mathrm{nm}$ ). The compositions of the $\mathrm{nBG}$ were very close to i) $45 \mathrm{~S} 5$ composition $\left(47.8 \mathrm{wt} \% \mathrm{SiO}_{2}\right.$, $25.1 \mathrm{wt} \% \mathrm{CaO}, 22.6 \mathrm{wt} \% \mathrm{Na}_{2} \mathrm{O}, 4.6 \mathrm{wt} \% \mathrm{P}_{2} \mathrm{O}_{5}$ ) [20], ii) 13-93 $\mathrm{BG}$ (53 wt.\% $\mathrm{SiO}_{2}, 20$ wt.\% $\mathrm{CaO}, 6$ wt.\% $\mathrm{Na}_{2} \mathrm{O}, 4$ wt.\% $\mathrm{P}_{2} \mathrm{O}_{5}, 12$ wt.\% $\mathrm{K}_{2} \mathrm{O}, 5$ wt.\% $\mathrm{MgO}$ ) and iii) 13-93-5Sr (mean particle size 30-35 nm) composition (53 wt.\% $\mathrm{SiO}_{2}, 15$ wt.\% $\mathrm{CaO}, 6$ wt.\% $\mathrm{Na}_{2} \mathrm{O}, 4$ wt.\% $\mathrm{P}_{2} \mathrm{O}_{5}, 12$ wt. $\% \mathrm{~K}_{2} \mathrm{O}, 5$ wt. $\% \mathrm{MgO}, 5$ wt.\% SrO). These glass nano powders were fabricated by the flame spray method $[20,21]$. 


\subsection{Preparation and characterization of soy protein films}

SPI films were prepared by the solvent-casting method. SPI solutions were prepared by dissolving $2 \% \mathrm{w} / \mathrm{v}$ SPI with constant stirring in ultra-pure water. It should be also mentioned that $2 \%(\mathrm{w} / \mathrm{v}) \mathrm{SPI}$ in water at $\mathrm{pH}$ around 7 was almost the maximum concentration of SPI which can be significantly dissolved in water and for higher concentration of SPI increase of the solution $\mathrm{pH}$ is inevitable $[8,22]$. Then the plasticizer $(2 \% \mathrm{w} / \mathrm{v}$ glycerol, w/w\% relative to SPI) was added to the solution under constant stirring. While being stirred, the solution was heated at a constant temperature of $60^{\circ} \mathrm{C}$ for $45 \mathrm{~min}$ and then $0.5 \% \mathrm{w} / \mathrm{v} \mathrm{nBG}$ was added. The blend solution was further subjected to an ultrasound treatment. The sonication treatment of the blend solution was carried out for $3 \mathrm{~min}$. A pulsed duty cycle of " $8 \mathrm{~s}$ on, $2 \mathrm{~s}$ off" was used. The parameters for ultra-sonication were optimized according to a previous investigation [23]. The ultrasonic treatment was applied with the probe type ultrasound source "20kHz Vibracell CV33" (Sonics \& Materials, USA). Finally, $25 \mathrm{ml}$ of the solution was cast into Teflon molds and dried at ambient temperature for 2-3 days. Subsequently, a thermal treatment at $80^{\circ} \mathrm{C}$ for $24 \mathrm{~h}$ was carried out in an oven. Dried films were then cut by punching in order to obtain pieces of circular shape (diameter $13.5 \mathrm{~mm}$ ). The nominal thickness of the dried films was 0.15-0.22 $\mathrm{mm}$.

Sodium dodecyl sulfate polyacrylamide gel electrophoresis (SDS-PAGE) was carried out for MP Biomedicals SPI solution by using the OmniPAGE TETRAD Package from Cleaver Scientific Ltd. The resolving gels (10\% acrylamide of about $1.5 \mathrm{~mm}$ thickness) were run at a constant voltage $(120 \mathrm{~V})$ and prepared according to the method described by Laemmli [24]. Proteins were visualized by Coomassie Brilliant blue G 250 staining using the Prestained Page Ruler marker (Thermo Scientific) for calibration.

\subsubsection{Physico-chemical properties of the films}

\section{i.Swelling and degradation behavior}

For swelling and degradation measurements the films were previously sterilized by UV light (power $(15 \mathrm{~W})$ ) for an hour. The dried SPI films $\left(\mathrm{W}_{\mathrm{d}}\right)$ with and without bioactive glass additions were incubated in Hanks' balanced salt solution (HBSS, Sigma-Aldrich, Germany) with $1 \%(\mathrm{v} / \mathrm{v})$ antibiotic-antimycotic for up to 28 days at $37{ }^{\circ} \mathrm{C}$. After specific time intervals, films were taken from the medium and then the remaining liquid adhered to the surfaces was removed from the samples, which were weighed $\left(\mathrm{W}_{\mathrm{t}}\right)$ with an analytical balance (Scaltec, 
Germany). The swelling and degradation of the films were calculated according to the following equation:

Swelling and degradation $(\%)=\left(\mathrm{W}_{\mathrm{t}}-\mathrm{W}_{\mathrm{d}}\right) / \mathrm{W}_{\mathrm{d}} \times 100$

where positive values are considered as swelling ( $\mathrm{w} \%)$ and negative values are considered as degradation ( $\mathrm{w} \%)$. Every experiment was repeated 5 times $(\mathrm{n}=5)$ and after calculating the swelling and degradation for each sample, the average values were determined.

\section{ii.Weight Loss}

The degradation of the films after 28 days of incubation in HBSS was investigated. The last time point was chosen at 28 days, according to the study reported by Peles et al. [8] which was considered a suitable time for studying weight loss of wound dressing biomaterials. The weight of the dried samples was measured before and after incubation. The percentage of weight loss was calculated using eqn. (2), where $\mathrm{W}_{\mathrm{i}}$ and $\mathrm{W}_{\mathrm{f}}$ correspond to the initial and final dried sample weights, respectively:

Weight loss $(\%)=\left(\left(\mathrm{W}_{\mathrm{i}}-\mathrm{W}_{\mathrm{f}}\right)\right) / \mathrm{W}_{\mathrm{i}} \times 100$

Every experiment was repeated 5 times.

\section{iii.Fourier transform infrared spectroscopy (FTIR)}

The chemical structure of the samples was assessed by FTIR (IRAffinity-1S, Shimadzu, Japan). The analysis was performed under the following conditions: spectral range between 4000 and $400 \mathrm{~cm}^{-1}, 32$ scans at a resolution of $4 \mathrm{~cm}^{-1}$ were recorded. SPI films with and without bioactive glasses of both soy protein films were used to record attenuated total reflectance Fourier transform infrared (ATR FTIR) spectra.

\section{iv.Scanning electron microscopy (SEM)}

The morphological analysis of the films was performed using scanning electron microscopy (SEM) (Auriga CrossBeam, Carl Zeiss Microscopy GmbH, Germany). The samples for SEM were sputter coated with gold (Sputter Q150T, Quorum Technologies, Darmstadt, Germany) before SEM examination. 
For SEM images of cells adherent on the 13-93 BG films after 5 days of cultivation, films were first washed with HBSS and fixation was conducted by using glutaraldehyde and paraformaldehyde composing fixation buffer. Then films were dehydrated in a graded ethanol series $(30,50,70,80,90,95$, and $99.8 \mathrm{v} \%)$. At the end the films were critical-point dried (Leica EM CPD300, Germany) and sputter-coated with gold prior to SEM examination.

\section{v.Clotting assay}

Blood clotting experiments were performed to analyze the hemostatic properties of films with different bioactive glasses. The clotting assay was conducted according to the following protocol [25]. First, membranes were pre-warmed in a $37^{\circ} \mathrm{C}$ incubator in polypropylene tubes. Then, $200 \mu \mathrm{l}$ citrate whole blood was added to all membranes. Also $20 \mu 10.2 \mathrm{M} \mathrm{CaCl}_{2}$ (starting coagulation) was added. Afterwards, all tubes were incubated at $37^{\circ} \mathrm{C}$ and $30 \mathrm{rpm}$ (orbital shaker) for $10 \mathrm{~min}$. Then the membranes and clots were removed and non-clotted blood was added into $25 \mathrm{ml}$ distilled water (by putting the open $1.5 \mathrm{ml}$ tubes into a $50 \mathrm{ml}$ falcon tube with $25 \mathrm{ml}$ distilled water) and it was shaken gently for $1 \mathrm{~min}$. Thereby, non-clotted blood was hemolyzed. Remaining fragments of the clot were pelleted by centrifugation at $200 \mathrm{~g}$ for $5 \mathrm{~min}$. Finally, the absorption of hemolyzed blood was measured at $540 \mathrm{~nm}$. The control was performed also in polypropylene tubes without the membrane.

\section{vi.Tensile mechanical properties}

Standard tensile strength testing was performed on SPI films (made from NowSports soy protein isolate) with and without three different kinds of nBGs with dimensions of $40 \mathrm{~mm} x$ 5mm using a Z050 machine (Zwick Roell, Germany). The films were held tightly between two metal restraints with a gauge length of $20 \mathrm{~mm}$ and in order to avoid damage while inserting the samples, the ends were covered with tissue paper. After an initial load of $0.1 \mathrm{~N}$ the measurements were carried out using a loading speed of $1 \mathrm{~mm} / \mathrm{min}$. Subsequently, a load of $50 \mathrm{~N}$ at a speed of $10 \mathrm{~mm} / \mathrm{min}$ was applied until failure occurred. The Young's modulus was estimated from the slope of the stress versus strain curves. Every experiment was repeated 4 times $(n=4)$.

\section{vii.Thermogravimetric analysis}

Thermogravimetric analysis was carried out with a SETARAM SETSYS TG-DTA 16/18 instrument. Samples were placed in alumina crucibles. An empty alumina crucible was used as reference. SPI films made from NowSports (with and without nBGs) were heated from 
ambient temperature to $700{ }^{\circ} \mathrm{C}$ in a $50 \mathrm{ml} / \mathrm{min}$ flow of $\mathrm{N}_{2}$ at a heating rate of $10{ }^{\circ} \mathrm{C} / \mathrm{min}$. Continuous recordings of sample temperature, sample weight and heat flow were taken.

\subsubsection{In vitro cell study}

The prepared circular films of SPI (MP Biomedicals) with and without nBGs were placed in 24-well plates. For sterilization, films were exposed to UV irradiation for an hour. All films were then pre incubated in Dulbecco's Modified Eagle Medium (DMEM), 10\% Fetal Calf serum (FCS) and 1\% antibiotic (penicillin and streptomycin) during night.

Mouse embryonic fibroblast cells (MEF cells) were grown in cell culture flask containing DMEM, 10\% FCS, 1\% non-essential amino acids and 1\% antibiotic (penicillin and streptomycin) for 48 hours. Afterwards the cells were harvested by trypsin and 50,000 cells were seeded per each sample and incubated in a humidified atmosphere of $95 \%$ relative humidity and $7.5 \% \mathrm{CO}_{2}$, at $37{ }^{\circ} \mathrm{C}$ for 2 and 5 days. To evaluate the growth and morphology of the selected cell density, MEF cells grown on standard cell culture plastic were used as a reference. The culture medium was changed after two days. To investigate the metabolism of the MEF cells on the films after 2 and 5 days of incubation, the viability of cells was evaluated by the WST-8 assay. To assess the viability of cells, live staining was performed with Vybrant ${ }^{\circledR}$ (DiI) (Thermo Fisher Scientific ${ }^{\mathrm{TM}}$, USA) and nuclei staining was done by blue nucleic acid stain, DAPI (Invitrogen ${ }^{\mathrm{TM}}$, USA). For higher clarity of images and better recognition, the blue nucleic acid stain was changed to green color. The images of VybrantDAPI stained cells were taken by fluorescence microscopy (Axio Scope A.1, Carl Zeiss Microimaging $\mathrm{GmbH}$, Germany).

\section{Results and discussion}

\subsection{SDS-PAGE}

The SPI solution was characterized by SDS-PAGE electrophoresis in order to analyze its molecular weight $(\mathrm{kDa})$. Results are shown in Fig. 1a, 1b. As it is observed in Figure 1b and according to Silva et al. [26], both SPI solutions illustrate the main band for glycinin polypeptides and subunits of $\beta$-conglycinin. $\beta$-conglycinin with trimeric structure is composed of three major subunits, namely $\alpha, \alpha^{\prime}$ and $\beta$, with masses of about 70 ( $\alpha$ and $\alpha^{\prime}$ subunits) and $48 \mathrm{kDa}(\beta)$, respectively $[27,28]$. In addition, soy glycinin with a molecular mass of approximately $350 \mathrm{kDa}$ consists of $6 \mathrm{~A}-\mathrm{B}$ subunits composed of an acidic polypeptide (A) and a basic polypeptide (B) linked by a disulphide bridge. The mass of the acidic polypeptide 
is about $38 \mathrm{kDa}$ and the basic polypeptide mass is about $20 \mathrm{kDa}$, which can be seen in Figure 1 as well [26,29].

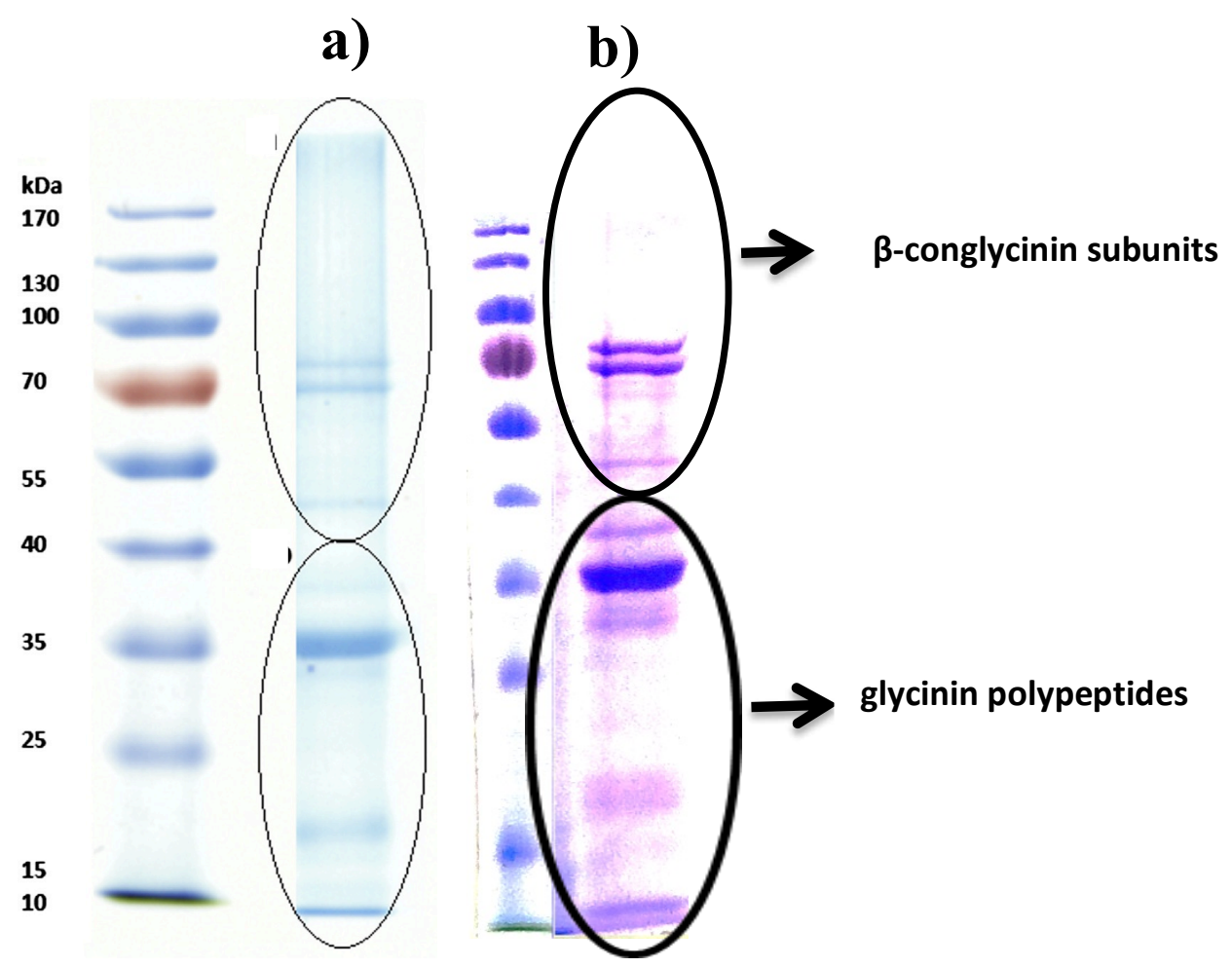

Figure 1: SDS-PAGE of both soy protein solutions, a) NowSports (Reproduced with permission from [26], Copyright 2018, Elsevier.) and b) MP biomedicals. Subunits of b-conglycinin and glycinin polypeptides are seen in the gels.

\subsection{Physico-chemical properties of the films}

\section{i. $\quad$ Swelling and degradation behavior}

In vitro swelling and degradation of the SPI (MP Biomedicals) films were investigated by measuring the weight gain and weight loss of the films during different incubation times in HBSS, at $37{ }^{\circ} \mathrm{C}$, in a controlled atmosphere of $5 \% \mathrm{CO}_{2}$ and $95 \%$ relative humidity. As shown in Figure 2, at the beginning of incubation, swelling of all films was observed, which was slightly higher for the films containing bioactive glasses. Then, a decreasing trend was observed, however this trend was not significant until 28 days of incubation. Removing the excess HBSS from the small SPI membranes before weighting was difficult. In that case, until 28 days of incubation, degradation is not detected, perhaps due to incomplete removal of the liquid from the samples. 


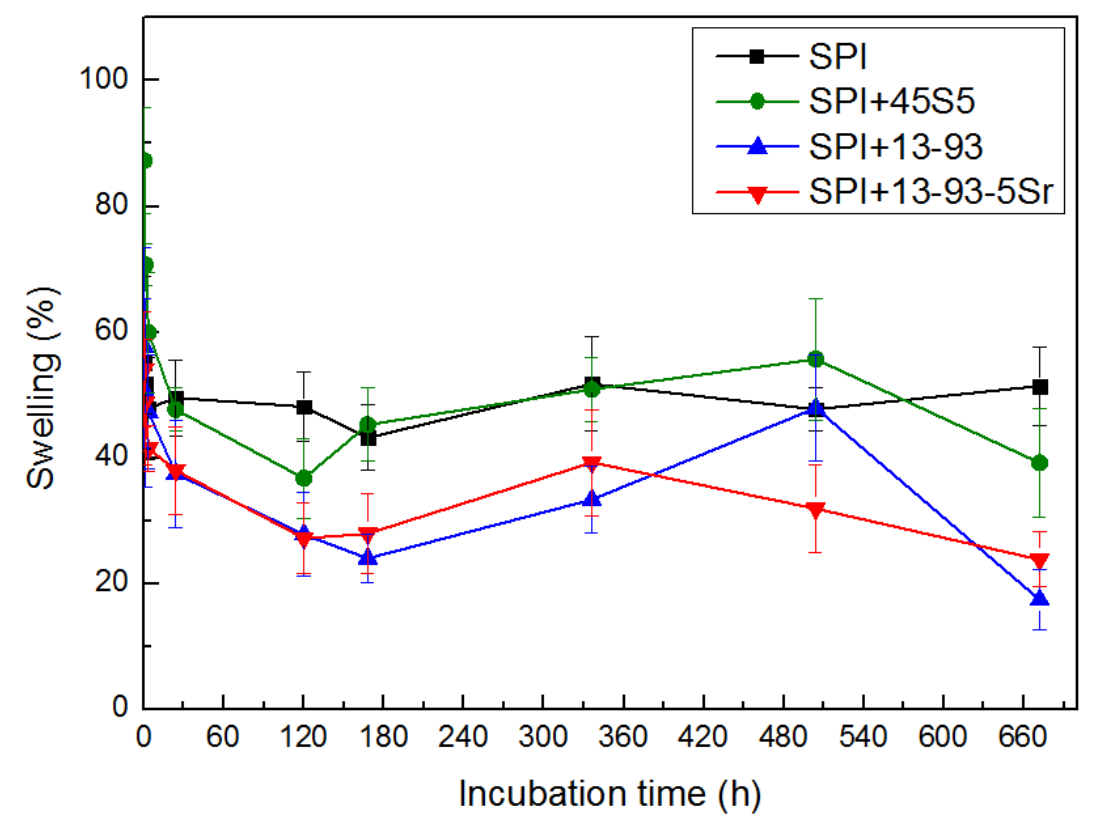

Figure 2: Swelling of SPI and SPI composite films during 28 days of incubation in HBSS, indicating no degradation of the samples.

\section{ii. Weight loss}

The weight of dried films after 28 days of incubation was measured and the results (Figure 3) depict degradation of up to 55\% weight loss for all SPI films. However, this result showed no difference in the degradation rate regarding the addition of nBGs, which indicates that degradation is likely due to the release of SPI and not due to interaction of the HBSS with bioactive glass. Silva et al. [26] have reported similar results for SPI-alginate hydrogel films immersed in simulated body fluid (SBF).

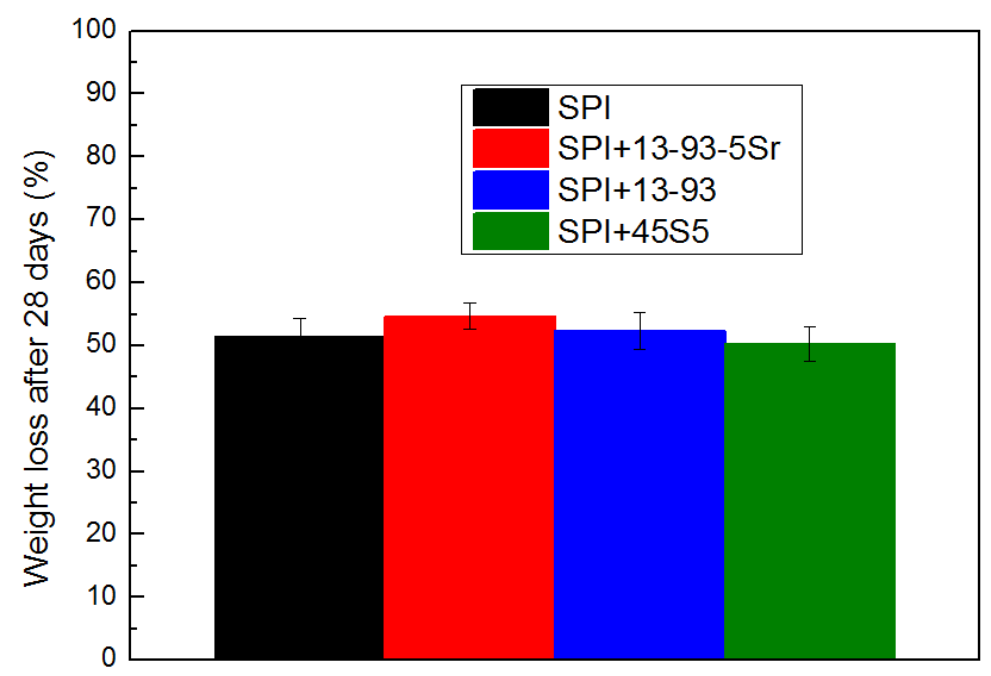

Figure 3: Weight loss of SPI and SPI composite films after 28 days of incubation in HBSS $(n=5)$. No significant difference was observed between all different types of films. 


\section{iii. FTIR study}

Figure 4 shows FTIR spectra of SPI films with and without BGs. The peaks of amides I, II, III and A are typical for proteins and they are all found in the FTIR spectrum of both SPI films (NowSports and MP Biomedicals). Amide I at $1645 \mathrm{~cm}^{-1}$ is typical for the $\mathrm{C}=\mathrm{O}$ stretching vibration [30,31]. Amide II at $1550 \mathrm{~cm}^{-1}$ belongs to the $\mathrm{N}-\mathrm{H}$ bending vibration and $\mathrm{C}-\mathrm{N}$ stretching vibration. The small peak for Amide III at about $1300 \mathrm{~cm}^{-1}$ relates to N-H bending vibration and C-N stretching vibration like Amid II [30,31]. The wide range from $3200 \mathrm{~cm}^{-1}$ to $3600 \mathrm{~cm}^{-1}$ belongs to the Amide A structure indicating the N-H stretching vibration [31,32]. Addition of $\mathrm{nBG}$ is not detected in the FTIR spectrum due to the covering with polymeric components of the films. This result is in agreement with the surface morphology of the films observed in SEM images (Figure 5) that show no nBG particle exposed on the surface.

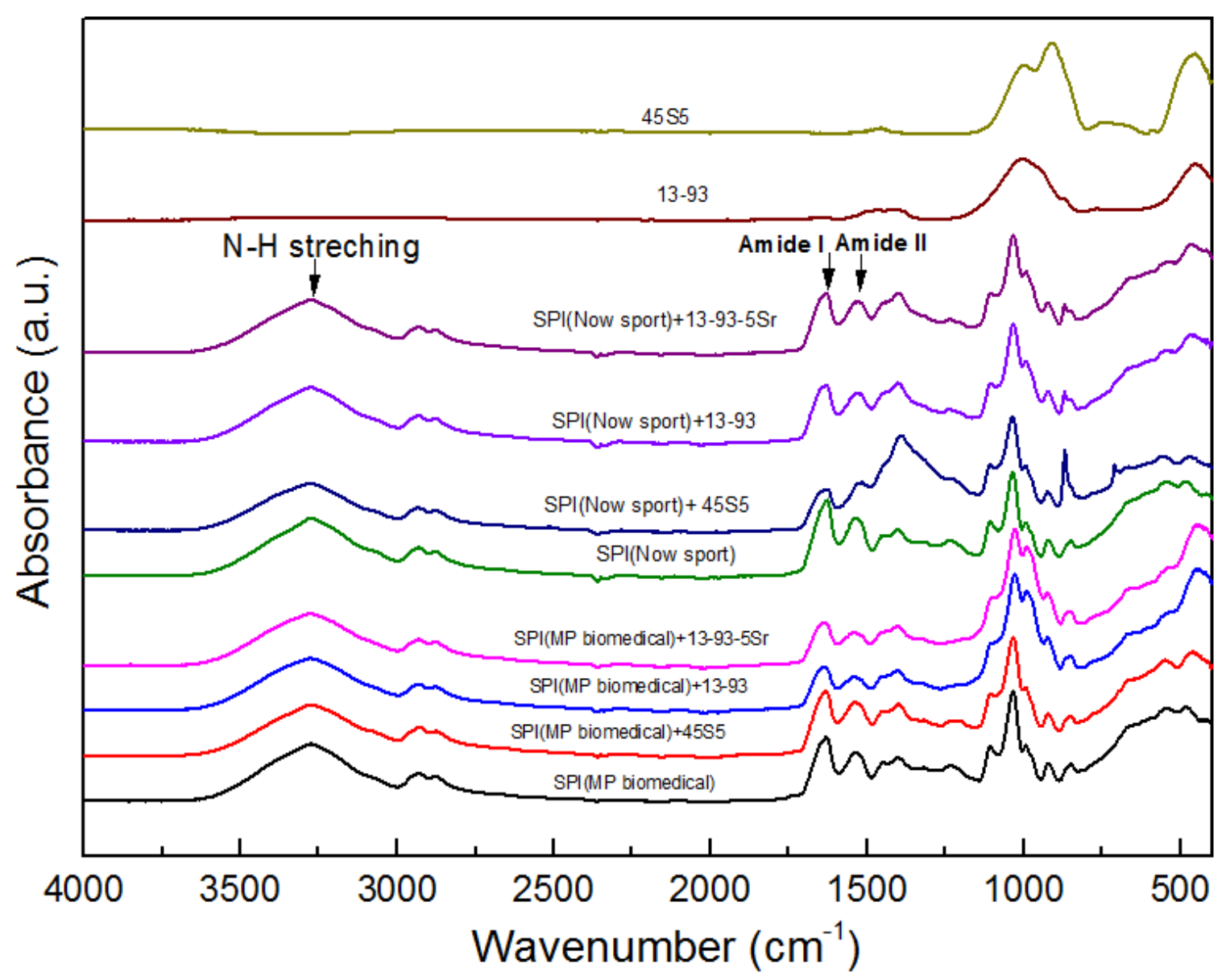

Figure 4: FTIR spectrum of both SPI films with and without nBG, relevant peaks are discussed in the text. 


\section{iv. SEM analysis}

The surface topography of SPI films (MP Biomedicals) was investigated by SEM (Figure 5). SPI films exhibited a smooth surface, while the addition of nBG led to a rough surface owing to the interaction between BG and protein. However, this interaction was stronger for $45 \mathrm{~S} 5$ and 13-93-5Sr nBGs in comparison to the 13-93 nBG. Tian et al. [33] have reported that silica nano particles changed the surface morphology of soy protein films to a rough surface. Moreover, silica exhibited uniform distribution in the protein matrix specially for contents below $15 \mathrm{wt} \%$ [33], which is observed in this study for the films with nBG.
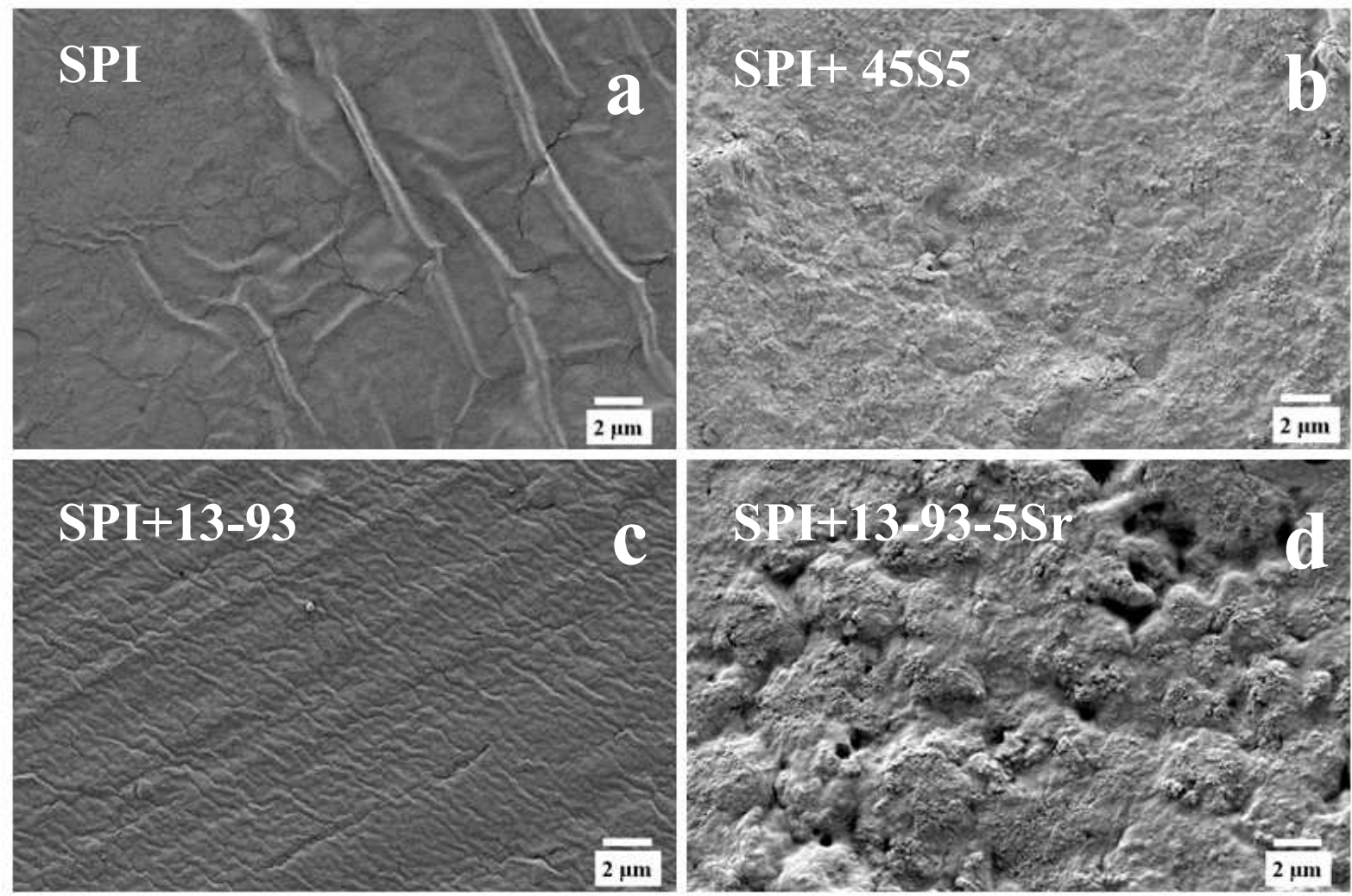

Figure 5: SEM images of SPI films (MP Biomedicals) with and without nBG, a) SPI, b) SPI/45S5, c) SPI/13-93, d) SPI/13-93-5Sr.

\section{v. Clotting assay}

The first stage of wound healing is hemostasis which starts by aggregation of platelets and clot formation to control bleeding [2]. A clotting assay was performed in order to understand the effect of $\mathrm{nBG}$ on the clotting ability of SPI-based films. Figure 6 shows the absorbance of non-clotted hemolyzed blood in water. Higher absorbance value indicates a slower clotting rate. As it can be seen in Figure 6 both SPI films without nBG and the control show similar 
results and they are not significantly different from each other, however, for the films with $\mathrm{nBG}$, a better coagulation effect is observed in comparison to the control, especially for 13-93 and 13-93-5Sr nBGs. Statistical analyses were accomplished by one-way analysis of variance (ANOVA) on all samples. The pairwise comparison of the means was performed with the Bonferroni's test (post hoc comparison). Both $\mathrm{Ca}^{+2}$ and $\mathrm{Mg}^{+2}$ ions play a critical role in stabilizing the conformation of coagulation factor IX in the blood-clotting cascade [34]. Moreover, Ostomel et al. [11] demonstrated that the fastest hemostatic response belongs to BG compositions with a high $\mathrm{Si} / \mathrm{Ca}$ ratio. In this case, SPI films with 13-93 and 13-93-5Sr nBGs show better clotting profile in comparison to SPI films with $45 \mathrm{~S} 5 \mathrm{nBG}$ especially for the MP Biomedicals SPI films, a result which might be due to the higher $\mathrm{Si} / \mathrm{Ca}$ ratio in both 13-93 and 13-93-5Sr nBGs in comparison to $45 \mathrm{~S} 5 \mathrm{nBG}$.

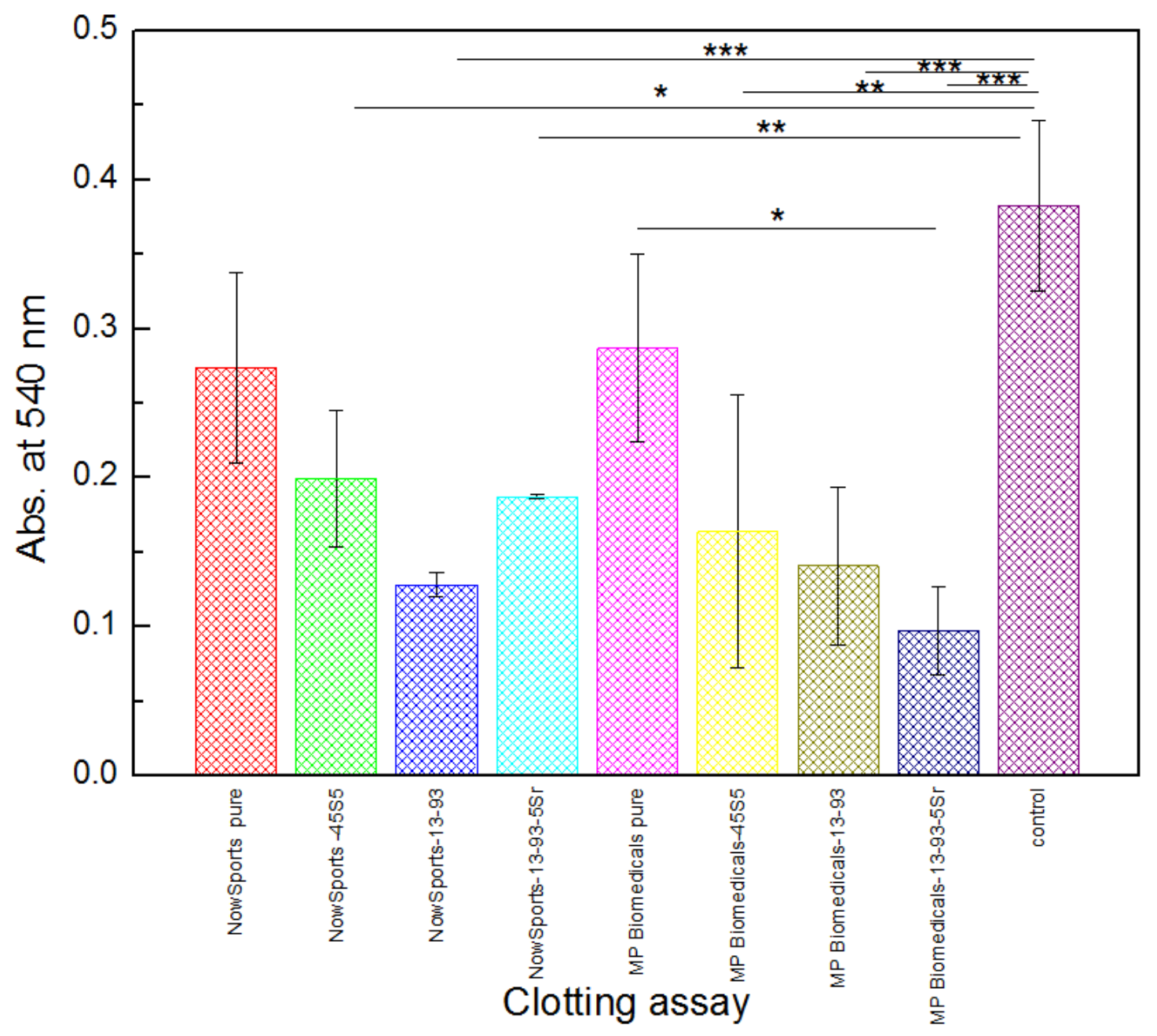

Figure 6: Clotting assay of both types of SPI films with and without nBGs. Significant differences are indicated in comparison to control: ${ }^{*} \mathrm{p}<0.05,{ }^{* *} \mathrm{p}<0.01$ and ${ }^{* * *} \mathrm{p}<0.001$ (Bonferroni's posthoc test $)(n=3)$. 


\section{vi. Mechanical properties}

The mechanical behavior of the SPI (NowSports) films with and without nBG was analyzed at room temperature. Table 1 shows the Young's modulus and ultimate tensile strength (UTS) values for different films. Typical curves are plotted in Figure 7. Normally the addition of inorganic filler should increase the stiffness and Young's modulus of polymeric films [35]. However, an increase of Young's modulus was not obtained in the present 45S5 and 13-935Sr films (Figure 8). The reason might be the poor interaction of these two nBGs with SPI leading to defects in the microstructure (e.g. internal cracks due to the lack of cohesion at the BG/SPI interfaces). Also SEM images confirmed that SPI+13-93 films had homogenous and smooth surfaces in comparison to the other films which could lead to higher Young's modulus.

Table 1: Mechanical characteristics of different SPI (NowSports) films with and without nBG.

\begin{tabular}{llccc}
\hline Films & SPI & SPI+45S5 & SPI+13-93 & SPI+13-93-5Sr \\
\hline Young's modulus [MPa] & $23.0 \pm 0.7$ & $10 \pm 1$ & $29 \pm 2$ & $20 \pm 4$ \\
UTS [MPa] & $3.70 \pm 0.09$ & $1.7 \pm 0.2$ & $4.7 \pm 0.4$ & $3.7 \pm 0.7$ \\
\hline
\end{tabular}

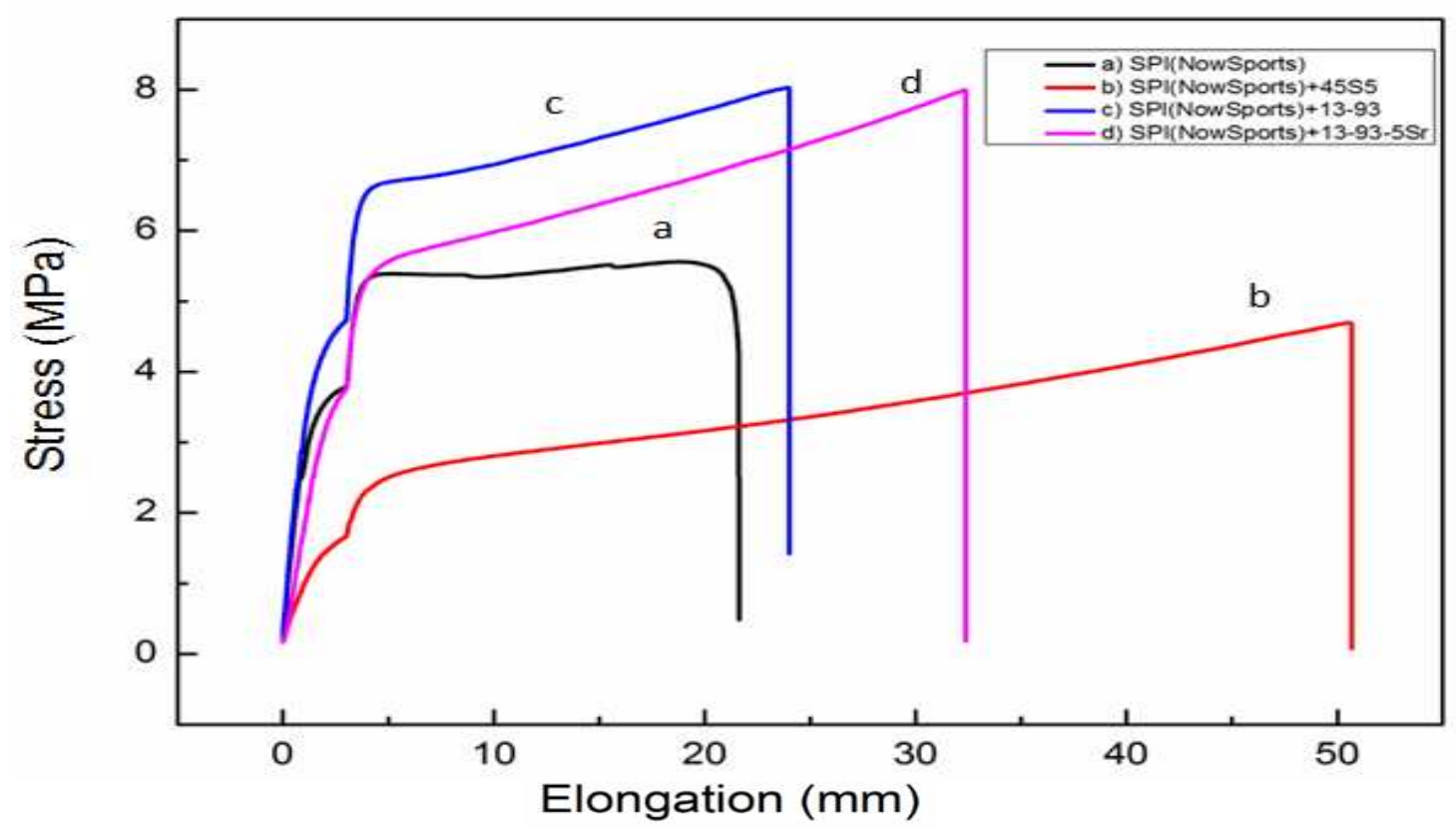

Figure 7: Typical stress vs strain curves of SPI (NowSports) composite 


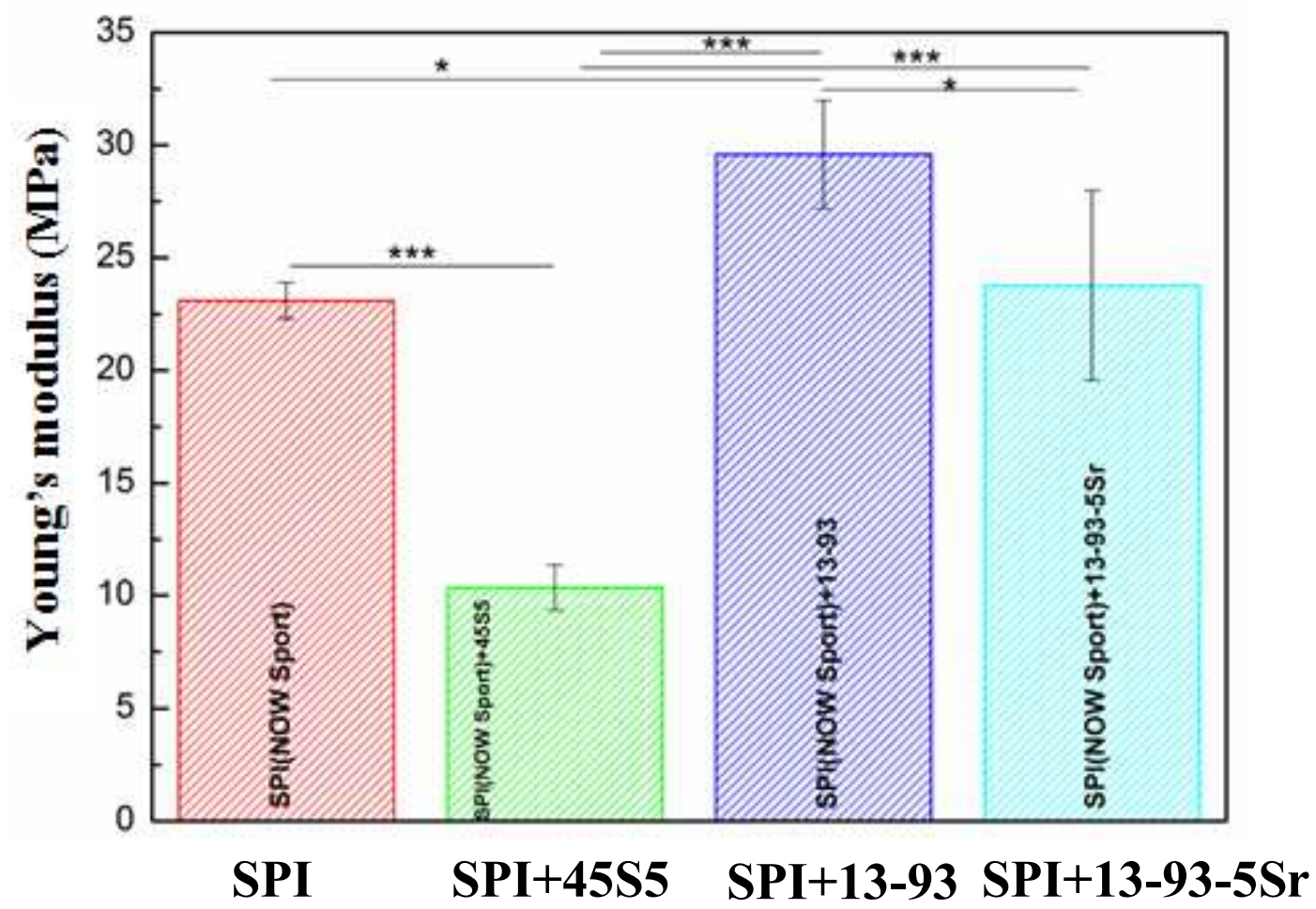

Figure 8: Young's modulus of SPI films (NowSports) with and without bioactive glass filler. Significant differences are indicated in comparison to control: ${ }^{*} \mathrm{p}<0.05,{ }^{*} \mathrm{p}<0.01$ and $* * * \mathrm{p}<0.001$ (Bonferroni's posthoc test).

\section{vii. Thermogravimetric analysis (TGA)}

TGA was performed to analyze the thermal stability of the composite films (NowSports). As expected, the results (Figure 9) show that BG is thermally stable in the temperature range between room temperature and $750{ }^{\circ} \mathrm{C}$. The evaporation of water in the temperature range between room temperature and $120{ }^{\circ} \mathrm{C}$, the evaporation of glycerol in the range between 120 ${ }^{\circ} \mathrm{C}$ and $280{ }^{\circ} \mathrm{C}$ and the SPI degradation above $280{ }^{\circ} \mathrm{C}$ were detected by TGA [33]. The total residual mass of approximately $10 \mathrm{wt} . \%$ at the end of the experiment belongs to the BG component considering the elimination of the organic phases of the sample. 


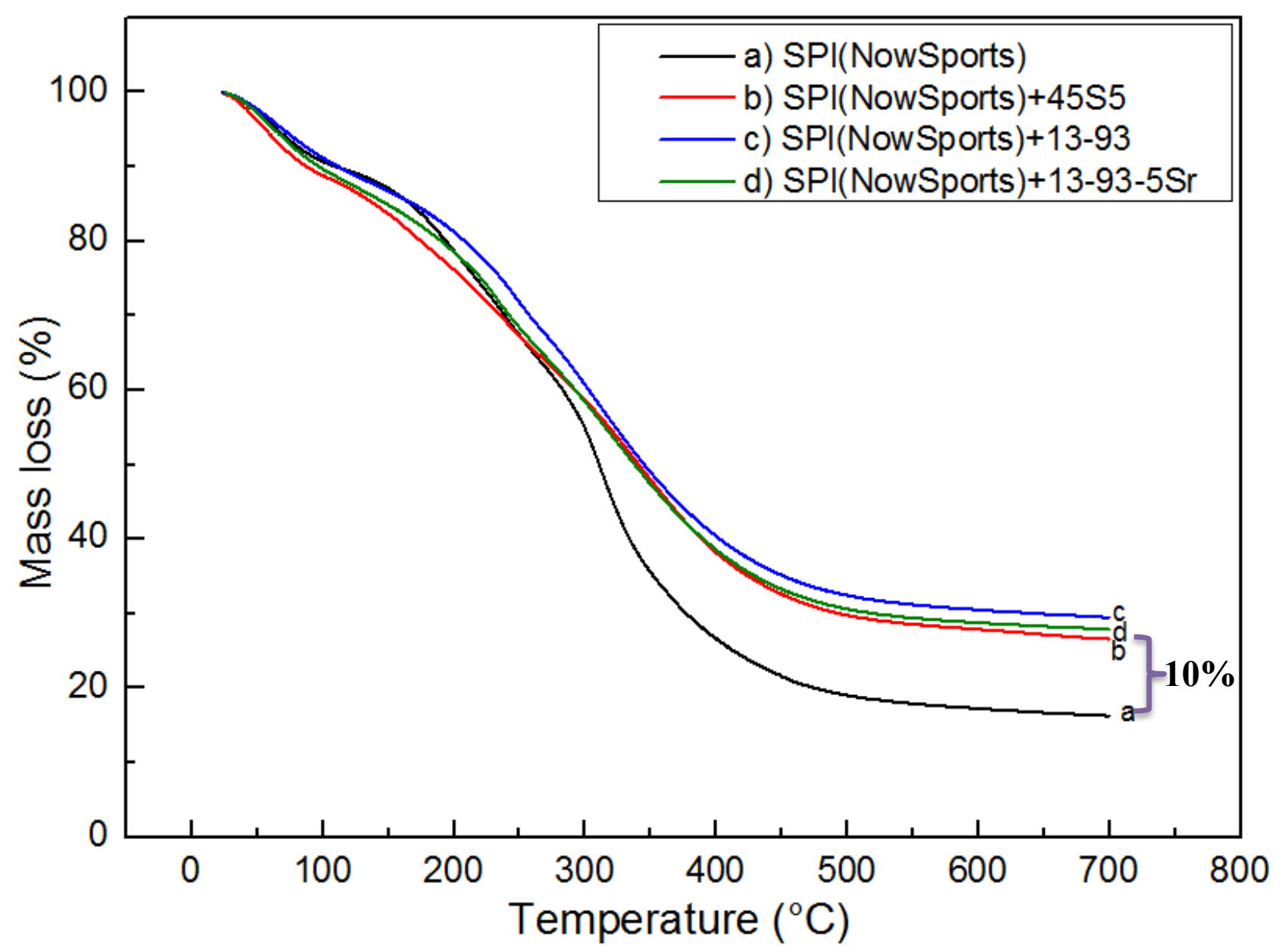

Figure 9: TGA of SPI (NowSports) composite films with and without BG.

\subsection{Cell culture study}

To investigate the metabolic activity of MEF cells on top of SPI films, the WST-8 test was performed. As shown in Figure 10, although the overall metabolic activity remained lower on SPI-based films than on standard cell culture plastic (for values on plastic, see Table 2), the presence of $\mathrm{nBG}$ in the films improved the mitochondrial activity of MEF cells after 2 days of cultivation. During the incubation time, the measured metabolic activity of MEF cells on all SPI films increased, owing to the proliferation of cells. Interestingly, the metabolic activity was significantly higher in cells grown on SPI-13-93 nBG composite films compared to the other types of films after 5 days of cultivation, possibly due to the better interaction of BG nanoparticles with SPI. SPI-13-93-5Sr nBG films showed also higher cell vitality after 2 days of incubation compared to pure SPI films, however, after 5 days incubation, a similar result 
for both SPI and SPI-13-93-5Sr nBG films was obtained. SPI+45S5 nBG films showed similar results to pure SPI films and the reason could have been the faster degradation of 45S5 nBG compared to BGs of the 13-93 composition family [36].

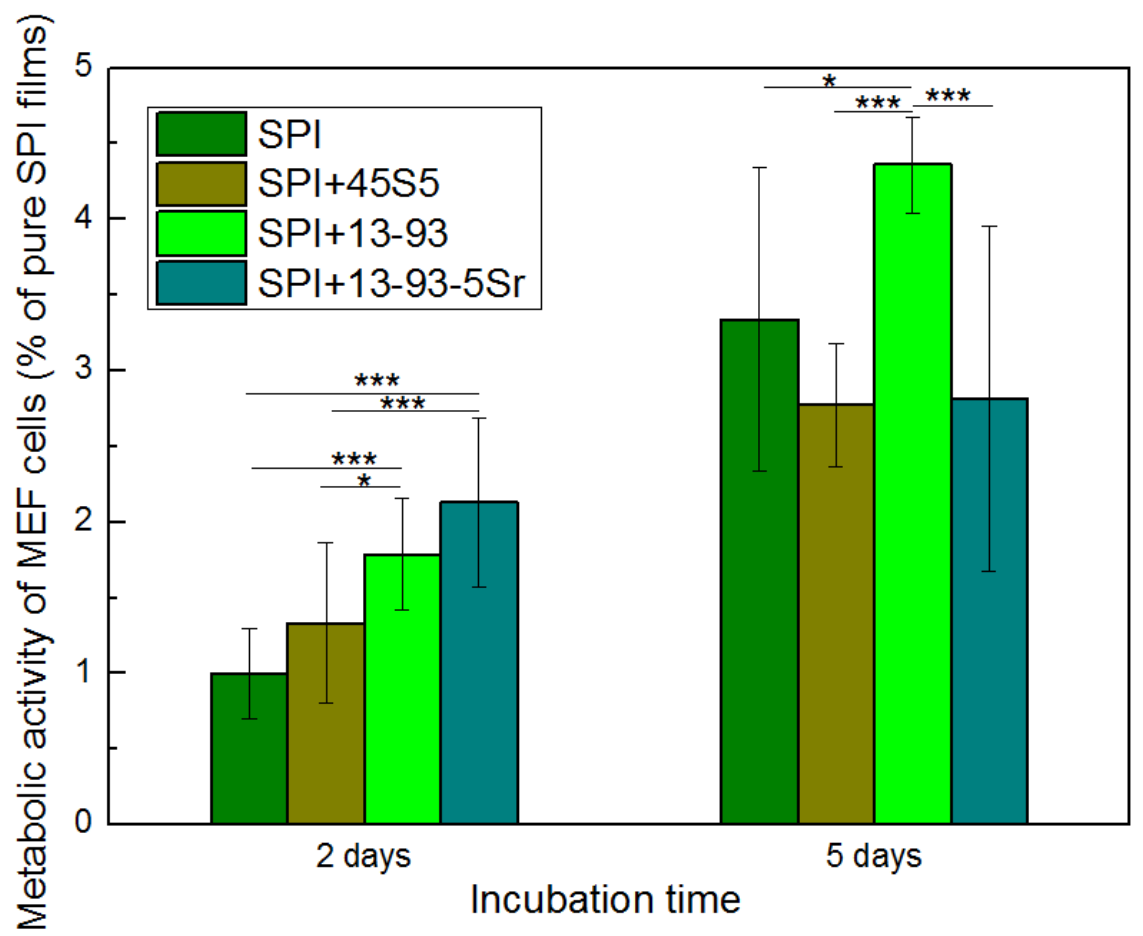

Figure 10: Metabolic activity of MEF cells on SPI films (MP Biomedicals) with and without BG fillers after 2 and 5 days of cultivation. Metabolic activity of MEF cells grown on pure SPI for 2 days was set to 1 . Significant differences are indicated in comparison to control: ${ }^{*} \mathrm{p}<0.05,{ }^{* *} \mathrm{p}<$ 0.01 and $* * * p<0.001$ (Bonferroni's posthoc test).

Table 2: Mitochondrial activity of MEF cells grown on standard cell culture plastic. Absorbance at $450 \mathrm{~nm}$, reflecting enzymatic conversion of tetrazolium salt (WST-assay), was measured on day 2, day 4 and day 7. Fold change relative of pure SPI values is shown \pm SD of hexaplicate samples.

\begin{tabular}{llll}
\hline Seeding density & Day $\mathbf{2}$ & Day $\mathbf{4}$ & Day 7 \\
\hline $\mathbf{3 0 , 0 0 0}$ cells/well & $8 \pm 0.5$ & $12 \pm 0.9$ & $11 \pm 0.3$ \\
$\mathbf{5 0 , 0 0 0}$ cells/well & $10.7 \pm 0.5$ & $14 \pm 0.6$ & $11 \pm 0.2$ \\
$\mathbf{1 0 0 , 0 0 0}$ cells/well & $10.2 \pm 0.8$ & $13.2 \pm 0.7$ & $11.4 \pm 0.4$ \\
\hline
\end{tabular}


The metabolic activity and morphology of living cells were in parallel evaluated by using Vybrant ${ }^{\circledR}$ (DiI), the lipophilic membrane dye which can easily stain the outer membrane of living cells [37]. In order to assess the integrity of the nucleus, a nucleic acid staining was performed using DAPI [38]. To obtain a better contrast, the blue color of the nucleus was digitally changed to green. Figure 11 shows a rapid growth of MEF cells and good surface coverage on the pure SPI (Fig. 11a, b) and on composite films containing nBG of 13-93 based-composition. The number of cells on top of the 13-93 group films was markedly higher compared to those on SPI-45S5 films after 2 days. Moreover, the results after 5 days of incubation (Figure 12) showed higher number of cells growing on pure SPI, SPI-13-93 nBG and SPI 13-93-5 Sr nBG films as compared to SPI-45S5 films. Notably, the fluorescent imaging of cells colonizing the surface of the $45 \mathrm{~S} 5 \mathrm{nBG}$-containing films after 2 days of incubation indicated a lower number of cells in comparison to the other types of films, which disagreed with the results of WST- 8 assay. According to the metabolic activity assay, the fluorescent imaging results of pure SPI films should be comparable to those of 45S5containing films. However, a lower number of cells was detected on the surfaces of SPI-45S5 BG films compared to pure SPI films, both after 2 and 5 days of incubation. Therefore, the surfaces of the well plates containing SPI-45S5 films were examined by fluorescent microscopy. As shown in the insert of Fig. 11, the presence of cell clusters on the bottom of the wells, under the 45S5 BG-containing films, was observed. This indicates that the rapid cell attachment to the SPI-45S5 nBG films surface was prevented, resulting in MEF cell growth below these films on the well plates. Such effect could be explained by different characteristics of these films, which did not closely stick to the bottom of the wells and were prone to bending after cell seeding, or due to an insufficient biocompatibility of the surface. The WST-8 results for this type of sample must therefore be treated with caution, and ideally, for the purpose of future investigations, the films should be transferred to a separate well plate before the metabolic activity measurements, to avoid interference from cells colonizing the bottom of the wells. It is important to note that this effect was not observed in any of the other films. 

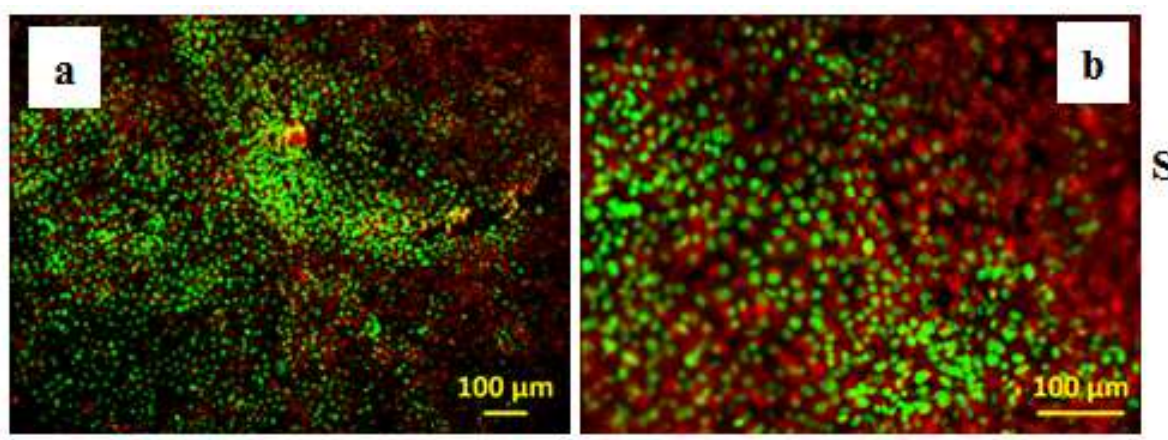

\section{SPI}
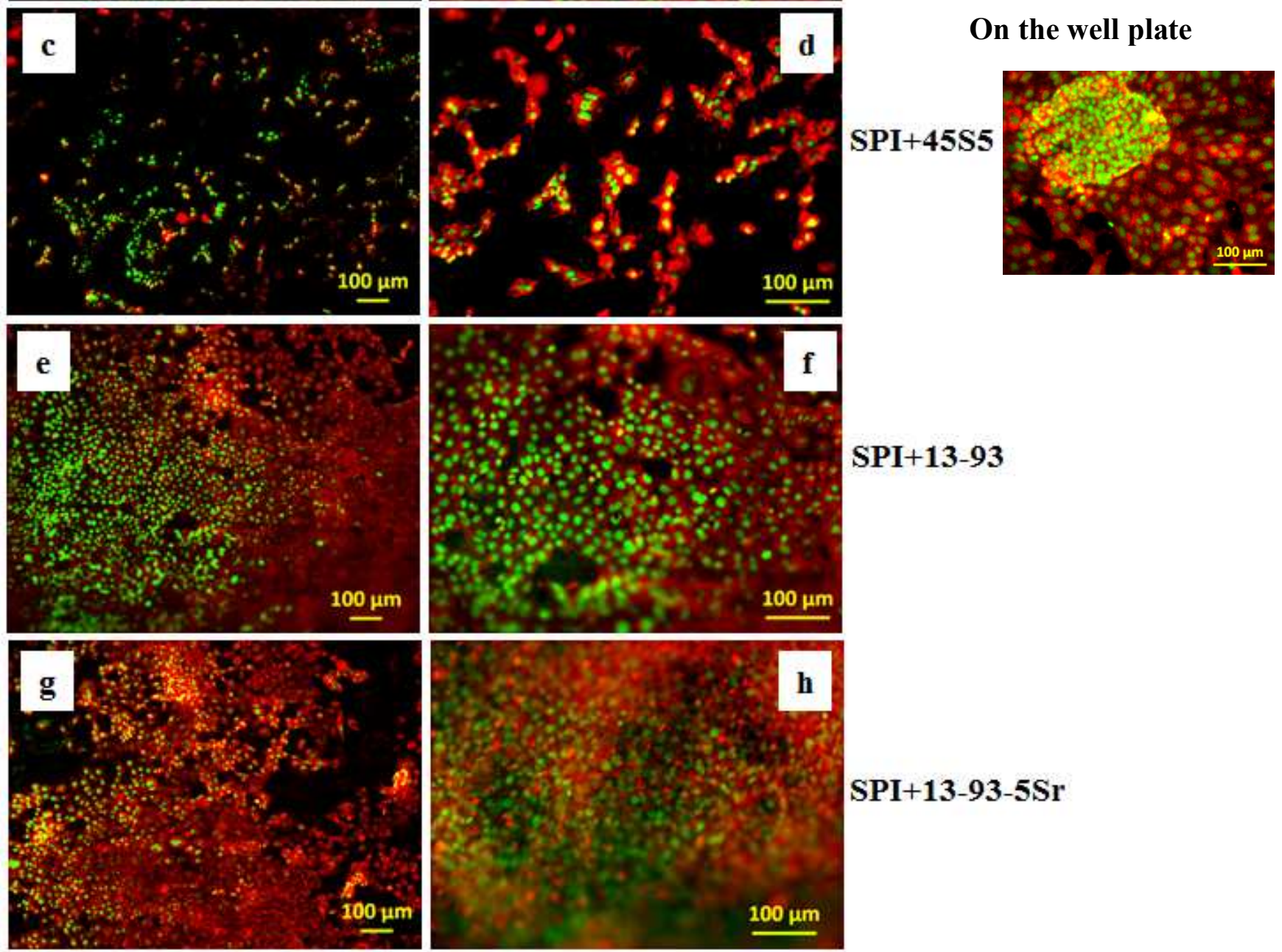

SPI+13-93-5Sr

Figure 11: Fluorescent staining with Vybrant-Dapi of MEF cells on the SPI (MP Biomedicals) composites films after 2 days.

Previous studies have indicated that the stiffness of the substrate could have an effect on the adhesion properties of fibroblasts [39,40]. More recently, a study on human fibroblasts showed a clear dependence of fibroblast adhesion and proliferation on the substrate elastic modulus [41]. The number of adherent cells after $24 \mathrm{~h}$ and 6 days post-seeding gradually increased with growing stiffness of the substrate surface, within the range of $0.5 \mathrm{MPa}$ and 120 MPa. In our study, the observed density of MEF cells grown on different substrates 
corresponds to the data in Figure 8, showing the Young's modulus of SPI composite films, which indicates a correlation between cell proliferation and mechanical properties of the films. The higher Young's modulus of pure SPI, SPI-13-93 nBG and SPI 13-93-5 Sr nBG films could therefore positively affect the cell viability compared to SPI-45S5 films, with Young's modulus of about $1 \mathrm{MPa}$. This might also be the reason explaining why films containing 13-93 nBG, due to their highest value of the elastic modulus, showed better cell attachment and proliferation compared to other films.
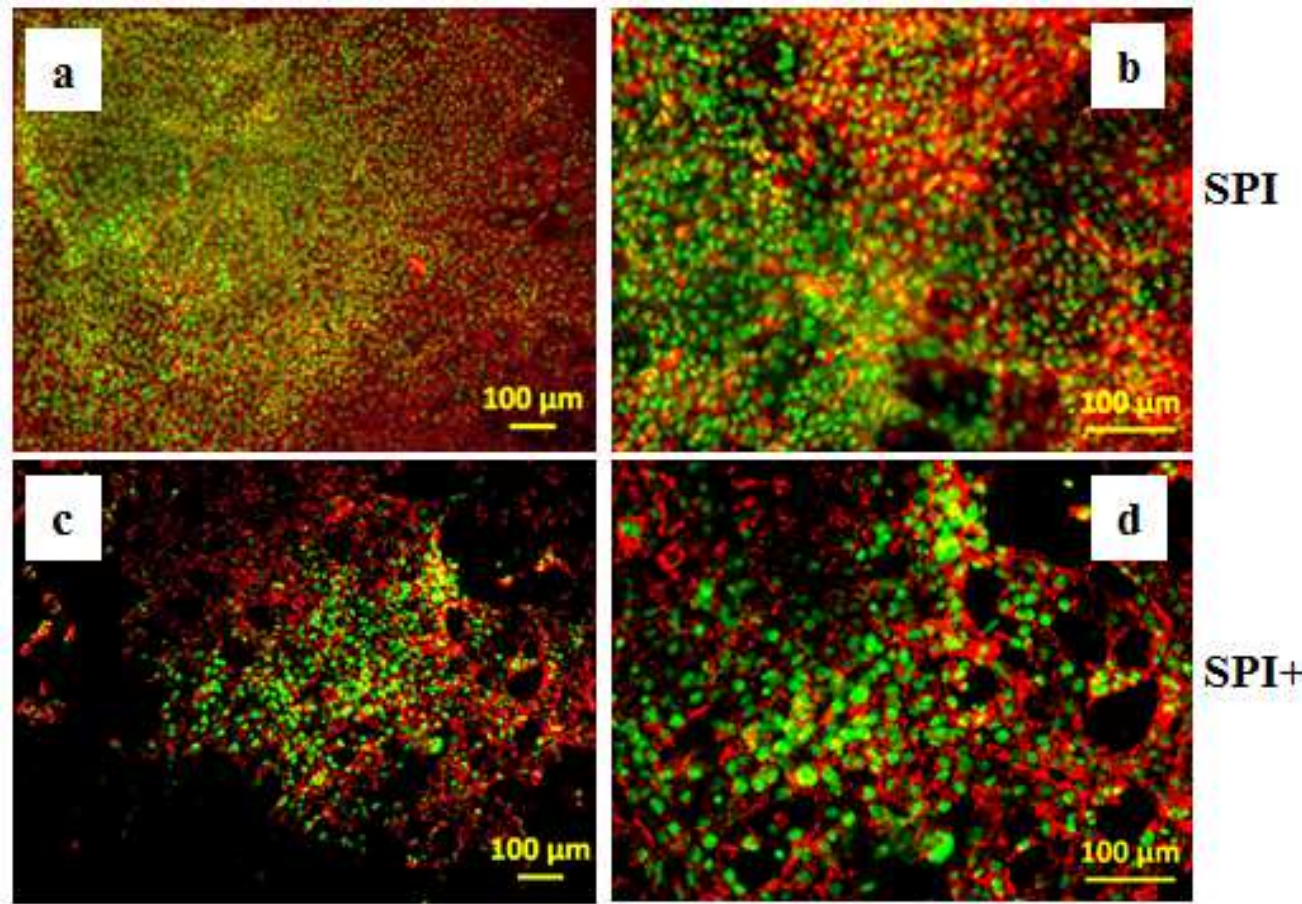

SPI+45S5
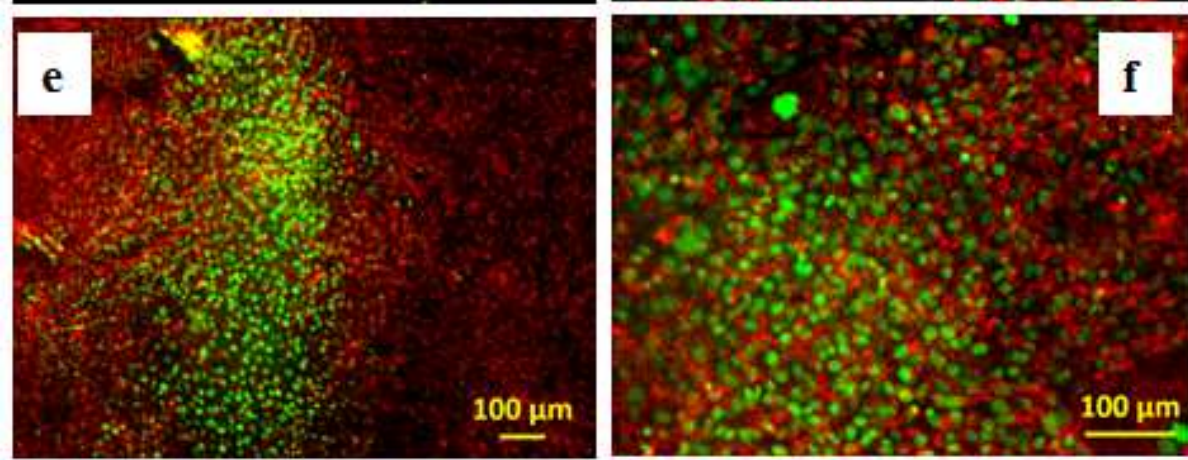

SPI+13-93
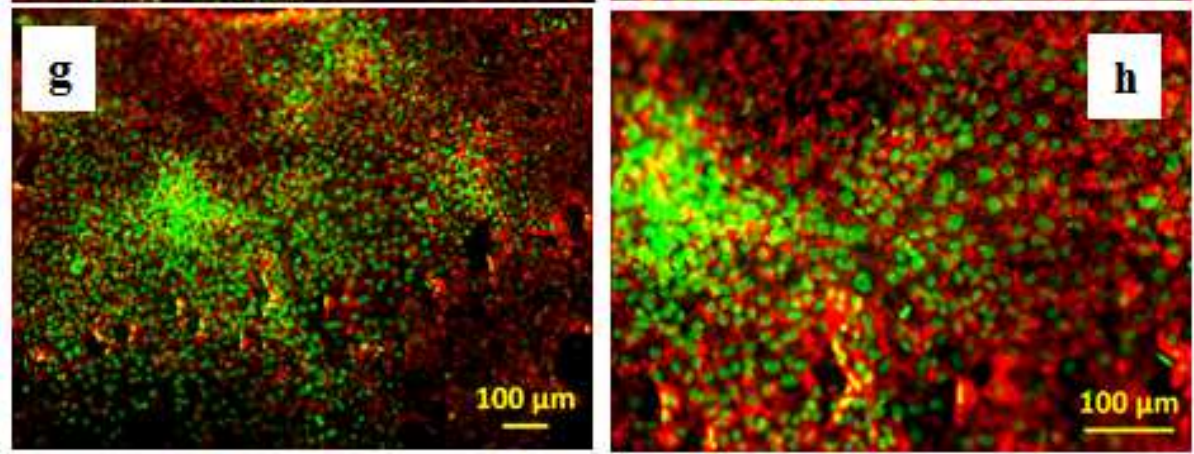

$\mathrm{SPI}+13-93-5 \mathrm{Sr}$

Figure 12: Fluorescent staining with Vybrant-Dapi of MEF cells on SPI (MP Biomedicals) films with $\mathrm{nBG}$ fillers after 5 days. 
The cytocompatibility of the 13-93 nBG films was also confirmed by SEM images (Figure 13). In Figure 13, multiple layers of MEF cells, which were anchored on the surface of 13-93 nBG films with their growing filopodia, are shown. These results seem to correlate with SEM images of the surface of the films (Fig. 5) showing the smoothest surface for SPI-13-93 nBG in comparison to the other composite films. Previous reports have shown that, whereas fibroblast attachment and proliferation are positively influenced on flat polystyrene cell culture dishes with increasing nanoscale roughness (ranging between 1-6 nm) [42], cell attachment and growth are progressively inhibited on substrates with surface nanoroughness of $30 \mathrm{~nm}$ and higher [43]. The relative smoothness of the SPI-13-93 nBG films could therefore be another reason for better cell attachment and proliferation on these samples.
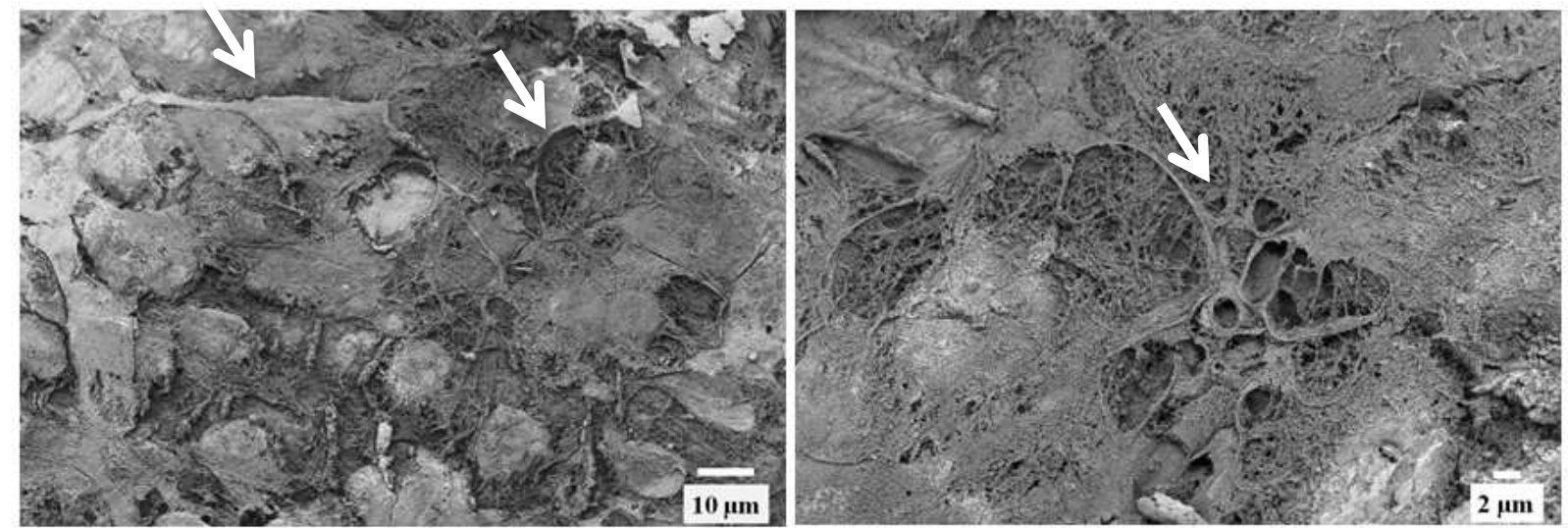

Figure 13: SEM images of MEF cells adherent on the 13-93 BG films after 5 days of cultivation.

a) lower and b) higher magnification. White arrows show the filopodia.

\section{Conclusions}

In this study, the development and characterization of novel biodegradable materials based on soy protein isolate composite films containing BG nanoparticles were presented. Degradation studies demonstrated up to 55\% weight loss during 28 days of incubation for all types of films. Being proposed for hemostatic wound dressing, a coagulation assay was performed on the samples, and results showed better blood coagulation for the SPI films containing BGs. Moreover, cell culture results indicated that MEF cells could grow better on SPI films containing BG especially for SPI-13-93 films compared to pure SPI films. The composition and surface topography of the films were the major factors influencing the cellular behavior. 
It can be thus postulated that these new SPI/BG composite films with appropriate cytocompatibility, together with their suitable mechanical and physical properties, offer high potential for use as wound dressings.

\section{Acknowledgment}

This paper is based in Chapter 3 of the $\mathrm{PhD}$ thesis of $\mathrm{S}$. Tansaz at Univ. of ErlangenNuremberg, Germany. The authors thank Alina Grünewald for technical support with cell biology studies, Prof. D. W. Schubert (Institute of Polymer Materials, University of ErlangenNuremberg) for granting access to laboratory facilities, Dirk Dippold for help regarding mechanical studies and thermogravimetric analysis and Supachai Reakasame for help concerning SDS-PAGE characterization.

\section{References}

[1] Z. Peles, I. Binderman, I. Berdicevsky, M. Zilberman, Soy protein films for wound-healing applications: antibiotic release, bacterial inhibition and cellular response, J. Tissue Eng. Regen. Med. 7 (2013) 401-412. doi:10.1002/term.536.

[2] S. Tansaz, A.R. Boccaccini, Biomedical applications of soy protein: A brief overview, J. Biomed. Mater. Res. Part A. (2015) n/a-n/a. doi:10.1002/jbm.a.35569.

[3] S. Tansaz, L. Liverani, L. Vester, A.R. Boccaccini, Soy protein meets bioactive glass: Electrospun composite fibers for tissue engineering applications, Mater. Lett. 199 (2017) 143146. doi:10.1016/j.matlet.2017.04.042.

[4] M. Santin, C. Morris, G. Standen, L. Nicolais, L. Ambrosio, A New Class of Bioactive and Biodegradable Soybean-Based Bone Fillers, Biomacromolecules. 8 (2007) 2706-2711. doi:10.1021/bm0703362.

[5] C. Morris, J. Thorpe, L. Ambrosio, M. Santin, The Soybean Isoflavone Genistein Induces Differentiation of MG63 Human Osteosarcoma Osteoblasts, J. Nutr. 136 (2006) 1166-1170. doi:10.1093/jn/136.5.1166.

[6] A. Merolli, L. Nicolais, L. Ambrosio, M. Santin, A degradable soybean-based biomaterial used effectively as a bone filler in vivo in a rabbit., Biomed. Mater. 5 (2010) 15008. doi:10.1088/1748-6041/5/1/015008.

[7] G.A. Silva, C.M. Vaz, O.P. Coutinho, A.M. Cunha, R.L. Reis, In vitro degradation and 
cytocompatibility evaluation of novel soy and sodium caseinate-based membrane biomaterials, J. Mater. Sci. Mater. Med. 14 (2003) 1055-1066. doi:10.1023/B:JMSM.0000004002.11278.30.

[8] Z. Peles, M. Zilberman, Novel soy protein wound dressings with controlled antibiotic release: Mechanical and physical properties, Acta Biomater. 8 (2012) 209-217.

doi:10.1016/j.actbio.2011.08.022.

[9] S. Tansaz, A.-K. Durmann, R. Detsch, A.R. Boccaccini, Hydrogel films and microcapsules based on soy protein isolate combined with alginate, J. Appl. Polym. Sci. 134 (2017) 1-9. doi:10.1002/app.44358.

[10] V. Miguez-Pacheco, L.L. Hench, A.R. Boccaccini, Bioactive glasses beyond bone and teeth: Emerging applications in contact with soft tissues, Acta Biomater. 13 (2015) 1-15. doi:10.1016/j.actbio.2014.11.004.

[11] T.A. Ostomel, Q. Shi, C.K. Tsung, H. Liang, G.D. Stucky, Spherical bioactive glass with enhanced rates of hydroxyapatite deposition and hemostatic activity, Small. 2 (2006) 12611265. doi:10.1002/smll.200600177.

[12] M. Gholipourmalekabadi, M. Sameni, A. Hashemi, F. Zamani, A. Rostami, M. Mozafari, Silver- and fluoride-containing mesoporous bioactive glasses versus commonly used antibiotics: Activity against multidrug-resistant bacterial strains isolated from patients with burns, Burns. 42 (2016) 131-140. doi:10.1016/j.burns.2015.09.010.

[13] A.A. Gorustovich, J.A. Roether, A.R. Boccaccini, Effect of bioactive glasses on angiogenesis: a review of in vitro and in vivo evidences., Tissue Eng. Part B. Rev. 16 (2010) 199-207. doi:10.1089/ten.TEB.2009.0416.

[14] J. Li, D. Zhai, F. Lv, Q. Yu, H. Ma, J. Yin, et al., Preparation of copper-containing bioactive glass/eggshell membrane nanocomposites for improving angiogenesis, antibacterial activity and wound healing, Acta Biomater. 36 (2016) 254-266. doi:10.1016/j.actbio.2016.03.011.

[15] R.M. Day, A.R. Boccaccini, S. Shurey, J.A. Roether, A. Forbes, L.L. Hench, et al., Assessment of polyglycolic acid mesh and bioactive glass for soft-tissue engineering scaffolds, Biomaterials. 25 (2004) 5857-5866. doi:10.1016/j.biomaterials.2004.01.043.

[16] S. Verrier, J.J. Blaker, V. Maquet, L.L. Hench, A.R. Boccaccini, PDLLA/Bioglass ${ }^{\circledR}$ composites for soft-tissue and hard-tissue engineering: an in vitro cell biology assessment, Biomaterials. 25 (2004) 3013-3021. doi:10.1016/j.biomaterials.2003.09.081.

[17] D. Moura, M.T. Souza, L. Liverani, G. Rella, G.M. Luz, J.F. Mano, et al., Development of a bioactive glass-polymer composite for wound healing applications, Mater. Sci. Eng. C. 76 
(2017) 224-232. doi:10.1016/j.msec.2017.03.037.

[18] W. Ma, X. Yang, L. Ma, X. Wang, L. Zhang, G. Yang, et al., Fabrication of bioactive glassintroduced nanofibrous membranes with multifunctions for potential wound dressing, RSC Adv. 4 (2014) 60114-60122. doi:10.1039/C4RA10232K.

[19] Q. Zeng, Y. Han, H. Li, J. Chang, Design of a thermosensitive bioglass/agarose-alginate composite hydrogel for chronic wound healing, J. Mater. Chem. B. 3 (2015) 8856-8864. doi:10.1039/C5TB01758K.

[20] T.J. Brunner, R.N. Grass, W.J. Stark, Glass and bioglass nanopowders by flame synthesis., Chem. Commun. (Camb). (2006) 1384-1386. doi:10.1039/b517501a.

[21] L.A. Strobel, N. Hild, D. Mohn, W.J. Stark, A. Hoppe, U. Gbureck, et al., Novel strontiumdoped bioactive glass nanoparticles enhance proliferation and osteogenic differentiation of human bone marrow stromal cells, J. Nanoparticle Res. 15 (2013). doi:10.1007/s11051-013$1780-5$.

[22] S. Tansaz, L. Liverani, L. Vester, A.R. Boccaccini, Soy protein meets bioactive glass: Electrospun composite fibers for tissue engineering applications, Mater. Lett. 199 (2017). doi:10.1016/j.matlet.2017.04.042.

[23] R. Silva, H. Ferreira, C. Little, A. Cavaco-Paulo, Effect of ultrasound parameters for unilamellar liposome preparation, Ultrason. Sonochem. 17 (2010) 628-632. doi:10.1016/j.ultsonch.2009.10.010.

[24] U.K. LAEMMLI, Cleavage of Structural Proteins during the Assembly of the Head of Bacteriophage T4, Nature. 227 (1970) 680-685. doi:10.1038/227680a0.

[25] S.Y. Ong, J. Wu, S.M. Moochhala, M.H. Tan, J. Lu, Development of a chitosan-based wound dressing with improved hemostatic and antimicrobial properties, Biomaterials. 29 (2008) 43234332. doi:10.1016/j.biomaterials.2008.07.034.

[26] R. Silva, B. Bulut, J.A. Roether, J. Kaschta, D.W. Schubert, A.R. Boccaccini, Sonochemical processing and characterization of composite materials based on soy protein and alginate containing micron-sized bioactive glass particles, J. Mol. Struct. 1073 (2014) 87-96. doi:10.1016/j.molstruc.2014.05.047.

[27] J.B. Coates, J.S. Medeiros, V.H. Thanh, N.C. Nielsen, Characterization of the subunits of $\beta$ conglycinin, Arch. Biochem. Biophys. 243 (1985) 184-194. doi:10.1016/0003-9861(85)907878 . 
[28] G.E. Sykes, K.R. Gayler, Detection and characterization of a new $\beta$-conglycinin from soybean seeds, Arch. Biochem. Biophys. 210 (1981) 525-530. doi:10.1016/0003-9861(81)90217-4.

[29] J.M.S. Renkema, H. Gruppen, T. Van Vliet, Influence of $\mathrm{pH}$ and ionic strength on heat-induced formation and rheological properties of soy protein gels in relation to denaturation and their protein compositions, J. Agric. Food Chem. 50 (2002) 6064-6071. doi:10.1021/jf020061b.

[30] K. Tian, Z. Shao, X. Chen, Investigation on thermally-induced conformation transition of soy protein film with variable-temperature FTIR spectroscopy, J. Appl. Polym. Sci. 124 (2012) 2838-2845. doi:10.1002/app.

[31] J. Kong, S. Yu, Fourier transform infrared spectroscopic analysis of protein secondary structures, Acta Biochim. Biophys. Sin. (Shanghai). 39 (2007) 549-559. doi:10.1111/j.17457270.2007.00320.x.

[32] W.K. Surewicz, H.H. Mantsch, D. Chapman, Determination of Protein Secondary Structure by Fourier Transform Infrared Spectroscopy: A Critical Assessment, Biochemistry. 32 (1993) 389-394. doi:10.1021/bi00053a001.

[33] H. Tian, Processing and properties of soy protein/silica nanocomposites fabricated in situ synthesis, J. Compos. Mater. 46 (2012) 427-435. doi:10.1177/0021998311422954.

[34] F. Sekiya, M. Yoshida, T. Yamashita, T. Morita, Magnesium(II) Is a Crucial Constituent of the Blood Coagulation Cascade, J. Biol. Chem. 271 (1996) 8541-8544. doi:10.1074/jbc.271.15.8541.

[35] J.B. Park, J.D. Bronzino, Biomaterials: Principles and Applications, CRC Press, 2002.

[36] M.N. Rahaman, D.E. Day, B.S. Bal, Q. Fu, S.B. Jung, L.F. Bonewald, et al., Bioactive glass in tissue engineering., Acta Biomater. 7 (2011) 2355-73. doi:10.1016/j.actbio.2011.03.016.

[37] A. Cselenyák, E. Pankotai, A. Csordás, L. Kiss, Z. Lacza, Live-Cell Fluorescent Imaging of Membrane or Mitochondrion Transfer between Connected Cells in Culture, Microsc. Sci. Technol. Appl. Educ. (2010) 764-771.

[38] Y.A. loannou, F.W. Chen, Quantitation of DNA Fragmentation in Apoptosis, Nucleic Acids Res. 24 (1996) 992-993. doi:10.1093/nar/24.5.992.

[39] J. Solon, I. Levental, K. Sengupta, P.C. Georges, P.A. Janmey, Fibroblast Adaptation and Stiffness Matching to Soft Elastic Substrates, Biophys. J. 93 (2007) 4453-4461. doi:10.1529/biophysj.106.101386.

[40] T. Yeung, P.C. Georges, L.A. Flanagan, B. Marg, M. Ortiz, M. Funaki, et al., Effects of 
substrate stiffness on cell morphology, cytoskeletal structure, and adhesion, Cell Motil. Cytoskeleton. 60 (2005) 24-34. doi:10.1002/cm.20041.

[41] I. Hopp, A. Michelmore, L.E. Smith, D.E. Robinson, A. Bachhuka, A. Mierczynska, et al., The influence of substrate stiffness gradients on primary human dermal fibroblasts, Biomaterials. 34 (2013) 5070-5077. doi:10.1016/j.biomaterials.2013.03.075.

[42] A.S. Zeiger, B. Hinton, K.J. Van Vliet, Why the dish makes a difference: Quantitative comparison of polystyrene culture surfaces, Acta Biomater. 9 (2013) 7354-7361. doi:10.1016/j.actbio.2013.02.035.

[43] C.P. Pennisi, A. Dolatshahi-Pirouz, M. Foss, J. Chevallier, T. Fink, V. Zachar, et al., Nanoscale topography reduces fibroblast growth, focal adhesion size and migration-related gene expression on platinum surfaces, Colloids Surfaces B Biointerfaces. 85 (2011) 189-197. doi:10.1016/j.colsurfb.2011.02.028. 